In this paper, I summarize an approach to language acquisition that has become extremely influential: language learnability. I argue that knowledge of this approach is beneficial to second language teachers. I present the major characteristics of the principles and parameters model of grammar as it has been applied to second language acquisition. The influence of philosophy (theories of mind), psychology (theories of learning), and linguistics (theories of language) is outlined. I conclude by discussing the research and pedagogic implications of this discipline.

\title{
INTRODUCTION
}

It is undeniable that language teachers benefit from knowing something about language learning. An understanding of the issues of language acquisition is essential to sound language pedagogy. Unfortunately, I think it is safe to say, that in the past few years the type of language acquisition research being done has become somewhat inaccessible to many language teachers. The area of inquiry known as language learnability has become a prominent research stream in both first and second language acquisition. And yet many teachers may feel that they do not have the necessary background to understand it. In this paper, I provide an overview of some of the major issues that must be considered in coming to understand work in language learnability.

I shall first argue that it is necessary to question the utility of empiricist, inductive, non-modular, constructivist learning theories and adopt a rationalist, deductive, modular, innatist theory. I shall then evaluate one such model, a parameterized model of language acquisition in the context of Pinker's (1979) conditions on formal models of language acquisition.

\section{What is a Grammar?}

We can probably avoid a fair amount of confusion by outlining from the beginning what linguists mean by the term grammar. A grammar is a description of the linguistic knowledge of a speaker of a particular language. Now, obviously, the knowledge that a speaker has can be described in a number of ways. What this leads us to is the notion of evaluating grammars to see which description is more highly valued. Chomsky provides some terminology related to the 
evaluation of proposed grammars which is useful. A grammar is descriptively adequate if it adequately describes the language in question. A grammar is explanatorily adequate if it goes beyond this and explains why the language takes the form it does and behaves the way it does. These are the two best-known criteria for evaluating grammars. But there is a third criterion which is going to be our major concern here: feasibility. The criterion of feasibility demands that a grammar actually be learnable under realistic conditions. So, for example, a grammar which could be arrived at only upon exposure to the entire language or which requires unrealistic memory capacity in the learner would not be feasible. Feasible grammars, then, are grammars which are learnable. This is what the field of learnability is concerned with.

\section{Learnability and Linguistics}

Most language teachers will be familiar with early models of transformational grammar. These models had large numbers of transformations with names like Dative Movement, Do Support, Relativization, and Passivization. This model described language quite well (i.e. was descriptively adequate). However, the question arose that if transformations are so unconstrained (i.e. can do anything) how can such a grammar possibly be learned? These models were not feasible. As a result, changes were made to reduce the power of transformations. Newer models have simpler, more general transformations (and consequently fewer of them). As the choice among transformations decreases, then, the learnability of the grammar increases.

Language learnability is a discipline concerned with theoretical linguistics and language acquisition. Traditionally, the study of both first and second language acquisition was primarily concerned with charting the developmental path of the learner (in a Piagetian fashion). Learnability research takes a different perspective. Rather than seeking to investigate the developmental path of the learner, we seek to investigate the universal endowment of the learner. By examining what a speaker knows about his or her languages we seek to explain how that knowledge could have been attained.

\section{The Theory of Grammar as a Theory of Mind}

The works of Chomsky (especially 1986, 1988) emphasize the connections between language and mind. A theory of grammar is a theory about a particular type of knowledge, which is represented in the minds/brains of individuals. This work has led to the realization that there must be an explicit connection between the theory of 
grammar and language acquisition (what has come to be called the "logical problem of language acquisition", see Baker, 1979, and Hornstein \& Lightfoot, 1981). This logical problem involves the minimal properties a grammar must have in order to be learnable, and to account for cross-linguistic diversity (see also Carroll, 1989).

\section{THEORIES OF MIND}

Before addressing the specifics of language acquisition, it is useful to look at a broader picture: philosophical views of mind and the acquisition of knowledge. These different positions on mind and knowledge acquisition will influence the view of language learning taken.

It is necessary to posit some form of mind in order to account for the behaviour of animate objects. Inanimate objects are governed by external forces, but animate objects' behaviour is governed by internal (as well as external) forces. There are, of course, many different views held as to how knowledge is acquired. As we will see, certain theories emphasize the role of experience while others emphasize the role of innate structures. Regardless of one's theoretical bias, all accounts must concern themselves with certain things. I would propose the following theory-neutral schema for the acquisition of knowledge:

$$
\text { Experience } \Rightarrow \text { Mind } \Rightarrow \text { System of Knowledge } \Rightarrow \text { Behaviour }
$$

Somehow, experience acts upon mind producing a system of knowledge that results in some sort of behaviour.

Different philosophers, however, view the mind in different ways. Two radically different views, which can perhaps best be seen as opposite extremes on a continuum, are empiricism and rationalism.

The current debate concerning empiricism and rationalism (see Mathews, 1989; Demopoulos, 1989) is similar to that between seventeenth century philosophers concerning the acquisition of concepts. Now, however, the subject matter is slightly different, focussing as it does on the acquisition of language. Language acquisition has become the battle ground for linguists, philosophers, and psychologists because, it is argued, this is the one domain where we have a good, independently motivated description of what is learned. Thus we can tackle such issues as how with more success.

Empiricists, such as David Hume, assign a major role to the environment in human learning. One of the most common metaphors for the mind in this paradigm is a tablet of hot wax. Everything in the mind is created by impressions from the outside 
world; from experience. This does not mean that the empiricists do not endow the mind with any innate structure, they do. However, they do not believe that the innate structure places any restrictions on the form of the knowledge to be acquired. It follows that the mind is capable of certain inductive procedures which place no restrictions on the class of grammars which can be acquired.

Contrasted with the empiricists are the rationalists, such as René Descartes, who endow the human mind with many innate capabilities. A metaphor for their view of the mind is a dark museum; whatever is in the museum is in there from the start, it just has to be found or activated. These two philosophical schools view language learning in somewhat different fashions. Consider the general schema of learning given earlier. If we apply this to language we produce:

Input Data $\Rightarrow$ Universal Grammar $\Rightarrow$ Language Specific Grammar $\Rightarrow$ Speech

The input data is the linguistic environment of the learner. Universal Grammar is the species-specific faculty that allows humans (and no other species) to learn language. The languagespecific grammar is the system of knowledge a speaker has about a particular language (e.g. Farsi or Vietnamese). Speech is one type of linguistic behaviour or output (it could also be writing or signing).

As Mathews (1989, p. 51) points out, the question that the rationalist-empiricist debate asks is "what sort of innate structure must be postulated in order to explain how, on the basis of the experience we have, we come to know what we know?" An empiricist language acquisition device would be a general learning mechanism which, we have seen, places no restrictions on the class of grammars which could be learned. A rationalist language acquisition device, on the other hand, is by definition, as Mathews $(1989$, p. 52) states, "severely restricted in the class of grammars it can acquire on the basis of access to data available to learners." A rationalist learning device limits the choices available to the learner in ways we shall look at later.

I will return to the issue of deciding between these two views of the language acquisition device throughout this paper. But it is interesting to note that Mathews (1989) feels that the whole issue was settled by Gold (1967) in his seminal paper "Language identification in the limit." Gold showed that there was no algorithm (learning procedure) which could uniquely identify the grammar of the language in question on the basis of sample 
sentences of the target language (see also Demopoulos, 1989). The fact that Gold was employing a maximally powerful learning strategy and still failed presents serious difficulties to an empiricist language acquisition device [which proposes powerful mechanisms to discover the grammar of any natural language (an infinite set) by analyzing a text in that language]. For Mathews $(1989$, p. 61) it is the death knell of an empiricist view of acquisition:

The fatal difficulty with empiricist accounts of language acquisition should be clear: they claim that the learner is very powerful as regards the class of languages that he can acquire, but they attribute to this learner radically insufficient internal structure (in the form of constraints on hypotheses) for acquiring that class of languages on the basis of the postulated primary data. Empiricists have failed to understand that hypotheses about input, output, and internal structure go hand in hand: an acceptable theory of language acquisition cannot attribute to the learner rich output, impoverished input, and minimal internal structure. In matters of learning, as elsewhere, one does not get something from nothing.

\section{IINDUCTION VERSUS DEDUCTION}

In this section I am going to outline the two major schools of thought regarding mechanisms of language acquisition: the inductive and the deductive view. These theories differ greatly in their conception of the learner. On the one hand we find theorists who maintain that language learning can be accounted for by principles of general learning (the inductivists) and on the other hand we find those who maintain that language-specific learning mechanisms must be posited (the deductivists). Ultimately, I will argue that we must reject a general learning theory and work within a language-specific, innatist framework of parameterized universal grammar.

An empiricist learning device proceeds by induction. Induction is a process of deriving generalizations as to the properties of the input. It moves from the Particular to the General. In the case of language the Particular would be the linguistic input and the General would be the linguistic rules. An inductive procedure should be able to derive the rules underlying any input.

A rationalist learning device, on the other hand, proceeds by deduction. Deduction is a process of drawing conclusions from principles that are already known. It moves from the General to the Particular. In the case of language, the General would be 
Universal Grammar and the Particular would be the languagespecific grammar.

\section{MODULARITY OF MIND}

The issue of modularity currently receives a lot of attention in the areas of philosophy of mind and linguistics (see Garfield, 1987). A modular view of mind maintains that there are several different modules (or subparts) of the mind, each of which has different properties or characteristics. A non-modular view would maintain that the mind is governed by a series of general principles which apply to all cognitive domains. Chomsky (1983) sets the stage for the discussion of the question of modularity when he says:

There are a number of cognitive systems which seem to have quite distinct and specific properties. ... The language faculty is one of these cognitive systems. There are others. For example, our capacity to organize visual space, or to deal with abstract properties of the number system, or to comprehend and appreciate certain kinds of musical creation, or our ability to make sense of the social structures in which we play a role, which undoubtedly reflects conceptual structures that have developed in the mind, and any number of other mental capacities. As far as I can see. . . they appear to have quite specific and unique properties. (p. 33)

Chomsky (1984) outlines some of the characteristics of modular approaches to the study of mind. He introduces the metaphor of mental organs (analogous to the organs of the body) to capture the idea that the various cognitive systems are separate. He notes that the traditional Cartesian view (1664) is that there is no modularity; that the "mind is entirely indivisible." This view is also adopted by a range of people from Skinner to Piaget (which, as Chomsky notes, includes just about everyone). Piaget does assume a kind of modularity in that there are stages of cognitive development. But for each stage the principles proposed are uniform across all domains.

As a general argument, Chomsky (1984, p. 16) suggests that "every complex biological system we know is highly modular in its internal structure. It should not be a terrible surprise to discover that the human mind is just like other complex biological systems: that it is composed of interacting sub-systems with their specific properties and character and with specific modes of interaction among the various parts." 
Probably the best known proponent of a modular view of the human mind is Jerry Fodor, particularly his 1983 monograph, The Modularity of Mind. A modular view maintains that different mental faculties are governed by specialized mechanisms. So, for example, such faculties as vision, language, and remembering each have unique characteristics; there is no general psychological mechanism. Jackendoff (1987) also maintains a modular position.

\section{Evidence From Abnormal Acquisition}

Curtiss (1988) presents some interesting evidence from abnormal language acquisition for the modularity hypothesis. She discusses the tragic case of Genie, an abused girl (Curtiss, 1977). Genie was discovered by the authorities at the age of thirteen. Until that time in her life she had been kept confined in an attic and had not been allowed to make any noise. Nor was anyone allowed to speak to her. In addition, she was severely malnourished when discovered. Not surprisingly, Genie had not acquired language in her state of captivity. Upon being placed in the care of the state, however, Genie received a great deal of professional help and attention. By looking at Genie, Curtiss (1988) finds some support for modularity. Genie's utterances had severe grammatical problems such as little inflectional morphology, omission of obligatory constituents, lack of syntactic devices marking embedding, etc. Some sample utterances (Curtiss 1988, p. 98) are:

Man motorcycle have.

Tummy water drink.

Genie bad cold live father house.

However, she did acquire some grammatical facts such as the correct subcategorization frames for most (but not all) verbs. Verbs are "subcategorized" as to what syntactic structures they can be part of. For example, a verb like give must be followed by both a direct and an indirect object ("I gave the book to Bob."). Genie also showed awareness of grammatical categories in that she never attached morphemes to the wrong base category. Genie showed impairment in certain structural aspects of language but not in the semantic component; evidence of a kind of modularity.

Curtiss (1988) offers evidence for modularity in the case of Chelsea. Chelsea is a severely hearing-impaired adult who, due to a lack of social services, did not begin to acquire her first language until she was in her early thirties (when she was fitted with hearing aids). Chelsea appears to have relatively normal non-linguistic 
cognitive and social abilities, and fairly good lexical abilities. However, she appears to have striking deficiencies in her syntax. Whereas Genie's sentences were semantically clear but ungrammatical, Cheisea's utterances seem to be both ungrammatical and uninterpretable. For example,

They are is car in the Tim.

Daddy are be were to the work.

The they.

However, she seemed to have mastered a number of discourse connectors such as "How are you?", "OK", and "well". Genie never mastered these kinds of social formulae. Curtiss concludes that in both Genie's and Chelsea's cases it seems that semantic acquisition, grammatical acquisition, and social abilities function separately.

She also cites evidence of a reverse profile to that shown by Genie and Chelsea. That is to say, there are also examples of individuals in whom grammar acquisition appears intact despite impairments in other components of linguistic development and despite significant and pervasive retardation. Antony had an estimated IQ of between 50 and 56, and had pervasive delays in motor, social, and cognitive abilities. However, his linguistic development outstripped his development in all other areas. Consider such sentences as:

It's not Vivian's, it's mine.

I don't want Bonnie coming in here.

However, his utterances were often semantically deficient (e.g. though he used tense markings, a single marker could be used to indicate past, present, or future), and he made frequent lexical errors (e.g. taking for dropping ). His pragmatic skills were also markedly deficient, in that he had trouble maintaining and controlling conversations. Thus, Antony presents evidence of grammar maturing independently of both other linguistic and nonlinguistic faculties.

There appears to be a considerable body of evidence to support a modular view of mind which claims that language is a separate cognitive domain. Thus, language acquisition must be explained with reference to principles which are specific to the language faculty, not by a set of principles constraining cognitive systems more generally.

Ultimately, then, our study of language and language acquisition 
can be seen as a window onto the mind.

\section{CONSTRUCTIVISM VERSUS INNATISM}

This is a debate between Jean Piaget, the founder of genetic epistemology, and Noam Chomsky, the founder of generative linguistics (see Piattelli-Palmarini, 1980). These two schools provide us with two different views as to the acquisition of language; Piaget provides us with constructivist explanations while Chomsky provides us with innate explanations. Both are examining the relationship between what is innate and what is acquired; between biological and cognitive structures. However, they take very different views of the child's mind. Piaget sees the child as an active constructive agent who slowly progresses in a kind of perpetual bootstrapping operation. Chomsky, on the other hand, sees the mind as a set of essentially preprogrammed units, each of which is equipped from the start to realize its full potential, and needing only a modest environmental trigger to exhibit its abilities. Chomsky views the mind as a collection of organs (like the heart or the liver). We don't think of the heart as "learning" how to beat, but as maturing according to a genetic timetable. He sees language in the same way; developing over time. In general, then, Chomsky is concerned with humanity's common innate endowment while Piaget is concerned with humanity's universal path of development.

Piaget describes himself as an anti-empiricist. His ontological commitments are halfway between the empiricist and the innatist traditions. Piaget's constructivist theory relies on the assumption that the structure of the environment (the milieu) can be transferred to the structure of the organism. It must be noted that practically all biologists disagree with this (see for example, Jacob \& Monod, 1961). Within the world of biology, it is accepted that one cannot pierce what is often called the genetic envelope of a given species except through random mutations occurring from the inside. These mutations are unrelated to any structure the outside world may offer.

Gardner (1980) summarizes Piaget's contributions as follows:

The phenomena he discerns offer a convincing series of snapshots of how development proceeds, but the specific terms he has devised and the models he has formulated have fared less well in the face of rigorous criticism. At most, Piaget's adventures into technical vocabulary and formal models offer a convenient way of synthesizing the enormous amount of data he has accumulated. In the end, it is his overall vision of how 
capacities relate and how knowledge in its varied forms develops that inspires workers in the field.

Chomsky, on the other hand, maintains that the environment has no structure, or at least none that is directly assimilable by the organism. Order is imposed on the perceptual world, not derived from it. The environment reveals this structure, it does not imprint its own patterns on the system. A rationalist account of language acquisition is based on the assumption that various (formal and substantive) universals are intrinsic properties of the language acquisition system. These properties provide a schema that is applied to the data and determine the grammar that may emerge upon presentation of appropriate data. Under this view, the data have a triggering action. They exert no formative action. Chomsky's claim is that we would not expect to discover a general learning theory any more than we would expect to discover a general growth theory.

\section{The Role of the Environment}

As innatist views of language acquisition have often been criticized for neglecting the role of the environment, I would like to discuss this issue briefly. Many of the general issues have been raised with respect to first language acquisition. When appropriate I will also refer to the issue with respect to second language acquisition. Chomsky (1983) makes two points clearly:

1. There is something in the human biological endowment that contributes to the growth of language in the mind.

2. The way in which language grows in the mind is going to be affected by the environment.

These points should be uncontroversial. However, to understand this particular view of the role of the environment, it is important to distinguish between a triggering and a shaping effect. Certain conditions in the environment may be necessary for a given system to develop, even though those conditions do not shape its development. Chomsky cites the example that mother-neonate interaction is necessary for the normal development of depth perception in sheep. In this case, the environment has a triggering effect on a biologically determined system. A shaping effect can be seen in the studies which have investigated how the characteristics of the visual field influence the development of the visual system. For example, cats who are exposed only to horizontal lines in their 
visual environments develop different visual apparatus than cats who are exposed to both vertical and horizontal lines.

Innatist theories emphasize the triggering role of the environment. As always, the researchers are open to considering explicit proposals as to how the environment shapes such linguistic features as question formation, etc., but in the virtual absence of such explicit proposals, there is little to argue against.

An argument for an innatist view of language is what is known as the poverty of the stimulus argument. This is a classical argument made use of by such thinkers as Plato and Descartes. Chomsky (1984, p. 19) summarizes this view as follows:

If we find that the mind is doing something in the absence of relevant experience, we have to attribute what it is doing to the intrinsic structure of the mind....

Lightfoot (1982) explicates this position clearly. The poverty of the stimulus argument is a biological style of argument used to identify genetic contributions; to tease out environmental contributions. The basic claim is that childhood experience is insufficient to explain the rich, complex adult language. No matter what language they are exposed to, children learn to utter and comprehend an infinite set of sentences. As Lightfoot points out, the stimulus is inadequate on three levels:

1. The speech the child hears does not consist solely of well-formed sentences. We find slips of the tongue, and incomplete thoughts. Even if only $5 \%$ of the data are defective this is an immense problem as the data do not come labelled as ungrammatical. Imagine how difficult it would be to induce the rules of a chess game if $5 \%$ of the moves were illegal, but you didn't know which $5 \%$. The input to the learner does not flag which sentences are grammatical and which are ungrammatical, and yet the child comes to be able to make this type of judgment consistently.

2. Children encounter a finite range of expressions when learning the language, but come to be able to deal with an infinite range of novel sentences (going far beyond what they heard in childhood) through such devices as relativization, subordination, and coordination. The input does not provide them with a list of every possible sentence in the language.

3. People come to know things subconsciously about their language for which no direct evidence is available in the data to which they are exposed as children. This is probably the most important deficiency. White (1989) provides examples of how certain aspects 
of language are underdetermined by the input; the linguistic knowledge goes beyond the input. One is the phenomenon of wanna-contraction in English. In certain environments the sequence want to can be contracted so that it is pronounce something like wanna. For example:

(1) I want to go. -> I wanna go.

(2) Who do you want to see? $\rightarrow$ Who do you wanna see?

But note that in the following example, the contraction is not allowed:

(3) Who do you want to feed the dog? -> *Who do you wanna feed the dog?

Children are not specifically told that sentences like (3) are ungrammatical, and yet they know. How do they know? It cannot be because the child never hears it; people say many things that they have not heard. How does the learner acquire this knowledge? There is nothing in the input that would indicate that the first two sentences are grammatical while the third is ungrammatical. So if experience cannot account for linguistic knowledge, some other source of knowledge must exist. Principles of UG can explain this seemingly arbitrary fact. If we look at the structure of two of these sentences, we find:

$W^{2} o_{i}$ do you want to see $t_{i}$ ?...

Who ${ }_{i}$ do you want $t_{i}$ to feed the dog? ${ }^{1}$

As White points out, wanna-contraction is sensitive to the presence of wh-traces. Contraction is blocked if there is a trace $(\mathrm{t})$ between want and to. Obviously this information is not available in the input (as traces are argued to have no phonetic value), and yet this UG knowledge that a trace is present is guiding the speaker's behaviour.

\section{Negative Evidence}

Another problem with the input that the learners receive has to do with how they learn about ungrammaticality. One possible answer is that the children make mistakes and are overtly corrected. This is what is referred to as negative evidence. This question has been addressed extensively in the first language acquisition literature (see Pinker, 1989a). Note that the assumption here is that (i) children get negative evidence, and (ii) children make certain kinds of mistakes. Regarding the first assumption, the classic study in this area, Brown and Hanlon (1970), showed that children do not usually get corrected when they make grammatical mistakes. Braine (1971) argued that even when they are exposed to negative evidence, they ignore it. Regarding the second assumption, it has become clear 
that there are many logically possible errors that children never make. I shall return to this when motivating parameterized universal grammar. This premise of no negative evidence is crucial to the work being done in learnability theory. The basic argument, as stated by Lasnik $(1989$, p. 89 ) is that "if the child does not have access to negative evidence-the information that certain structures are not part of the language - then Universal Grammar presumably does not make available choices that can only be resolved by such evidence."

\section{Caretaker Speech}

Another argument that is often presented against innatism is that of caretaker speech. This argument claims that the simplified speech addressed to the learner provides sufficient structure for language acquisition to take place on an inductive basis. In other words, that learners simply generalize patterns without the aid of genetically determined principles. Note, though, that in effect, this is just switching the genetic burden to the caretaker, who "happens" to know how to lead the learner along structurally; getting more and more complex with no overt knowledge of the structures in question. There are four major problems with the caretaker speech hypothesis (Gleitman, Newport \& Gleitman, 1984):

1. Children register only part of their environment and we have no way of knowing what each child registers. Children are not solely exposed to caretaker speech - they have other input.

2. Even if they only register well-formed utterances, the third data deficiency raised by Lightfoot still holds: some input is missing. Sentences like (iii) are not produced. Where does inductive generalization stop?

3. If the children registered only simplified and well-formed utterances, their job would be more difficult as their information would be limited.

4. Newport, Gleitman and Gleitman (1977) show that parents' speech to children has a high proportion of questions and imperatives. In this caretaker speech, declarative sentences are rarer than in ordinary speech. And yet the emerging language of the children does not reflect a similar bias. This suggests that there is no simple correlation between the emerging language of the children and the kind of language parents direct at the children.

Modified Input in Second Language Acquisition

These issues have also been addressed in second language acquisition research (see for example, Pica \& Doughty, 1985). 
Researchers have noted that the second language learners receive both modified input and modified interaction in comparison to native speakers. These styles have been referred to as foreigner talk (the input addressed to a non-native speaker by a native speaker) and teacher talk (the input addressed to a non-native speaker by a teacher). However, work in this vein in SLA suffers from the same problems as work in first language acquisition research. Parallel to Gleitman, Newport and Gleitman (1984) we could note the following facts about second language learners:

1. We have no way of knowing what each second language learner registers. The learners are not solely exposed to teacher talk or foreigner talk, either.

2. The input to second language learners is still deficient in many respects (Lightfoot's third deficiency).

3. If the learners hear only simple utterances their job will be more difficult.

4. The emerging grammar of the learner is affected by more than the grammatical characteristics of the input the learner receives (consider also the L1 linguistic structures).

\section{PARAMETERIZED MODEL OF LANGUAGE ACQUISITION}

Before I outline this model of language acquisition, I think it would be useful to present Pinker's (1979) conditions on formal models of language acquisition. These are the criteria which a viable theory of language acquisition must meet.

1. The learnability condition is met if the theory can account for the fact that languages can be learned.

2. The equipotentiality condition is met if the theory does not succeed merely by being extremely narrow; forcing many things to be specified as innate where they can be learned. The theory must be able to account for the acquisition of all languages.

3. The time condition is met if the theory accounts for learning in the time the learner normally takes for the acquisition of a grammar.

4. The input condition is met if the theory accounts for language learning with the typical input available to the learner.

5. The developmental condition is met if the theory makes correct predictions about the Icarner's capabilities during the course of acquisition.

6 . The cognitive condition is met if the theory agrees with the known cognitive faculties of the learner. 
All of the work cited above has shown that it seems to be necessary to question the utility of empiricist, constructivist, inductive learning theories and adopt a rationalist, innatist, deductive theory. I turn now to consider one such theory: parameterized universal grammar.

\section{Parameterized Universal Grammar}

As we have seen, Universal Grammar (UG) is the common human endowment related to language. Remember, that UG is a theory of knowledge not of behaviour. Williams (1987) provides a summary of the parameterized model: Universal rules, (or principles) are specified as innate. These principles are found in all human languages. But the rules "are slightly underspecified" - that is, certain parameters are left unspecified, to be filled in by the child according to the language he is exposed to" (vii). A common metaphor for the parameter is a light switch. The learner has certain universal principles (which are innate and hence not affected by the environment) and parameters (which need to be switched to a particular position depending on the language of the environment) guiding language acquisition. Parameter setting $\mathrm{x}$ will produce, for example, Spanish, while parameter setting $y$ will produce, for example, French. The parameter does not get set until the learner is exposed to the linguistic environment.

Let's look at a proposed parameter of UG discussed by Cook (1988): the head parameter. Principles account for what is in common between languages. We need parameters to capture the variation between human languages. One of the ways in which languages vary is the order of the elements in a sentence. We probably all remember the mechanism of Phrase Structure Rules from introductory linguistics courses. They looked something like this:

$$
\begin{aligned}
& \text { Verb Phrase } \Rightarrow \text { Verb }+ \text { Noun Phrase } \\
& \text { Prepositional Phrase } \Rightarrow \text { Preposition }+ \text { Noun Phrase }
\end{aligned}
$$

Note that all verb phrases have verbs in them, all prepositional phrases have prepositions in them, etc. These obligatory elements are known as the heads of a phrase. Languages vary in whether the head of a phrase is on the left or on the right. In English, the head of a verb phrase (the verb) is on the left: "borrowed a car."

The head of a prepositional phrase (the preposition) is on the left: "to the movies."

The head parameter in English, then, has the switch set to [left]. 
Not all languages behave in this fashion. Japanese, for example, has the head parameter set [right]. A literal translation of the above sentences from Japanese would read: "a car borrowed" and "the movies to."

The different parameter settings capture certain things about the structures of the different languages. And, as we shall see, it also gives us a way of describing the influence of the first language on the second language in second language acquisition.

So within a parameterized model of Universal Grammar, the child is not searching through an infinite number of possible grammars, as an inductive view might suggest, but is attempting to answer a few simple questions. For example, "is the head parameter of the language I'm learning set [left] or [right]?"

\section{Universal Grammar and Second Language Acquisition}

A parameterized model of second language acquisition attempts to account for (1) the contrastive errors (which seem to result from L1 interference) and (2) the constructive errors (which cannot be traced back to the L1). When we compare the L1 grammar with the L2 grammar, some of the parameter settings will be the same and some will be different. Where the parameters are set differently, L1 interference would be predicted. Thus, the contrastive element can be accounted for.

What of the constructive element? In Flynn's (1987) view, the fact that L1 and L2 learners sometimes produce similar errors is the result of the same deep underlying principles operating on the input data. Exposure to the data causes the parameters to be set in certain ways regardless of whether it is L1 or L2 data. While there are certain problems with Flynn's methodology (Bley-Vroman \& Chaudron, 1990), it still seems that the parameterized model can reconcile two seemingly irreconcilable aspects of second language acquisition.

In terms of parameters then, let us keep in mind three terms that refer to possible settings for the switch. There is the L1 setting (which is the setting that generates the first language). There is the L2 setting which is the setting that generates the second language). And there is also the term "default setting". This is a term borrowed from computer jargon. The default setting is the setting found in the absence of other evidence; the child comes into the world with the default settings of the parameters. The environment will present evidence as to whether the default setting is the correct one.

In the field of second language research, there is considerable 
debate as to just what aspects of the first language will transfer into the second language. Much of the debate hinges on the notion of markedness. I will not go into an extended discussion of markedness here. Suffice to say that the definitions given to the term vary wildly, and that it is an intuitively appealing but poorly formalized concept. Markedness has something to do with what is "natural" in language. A form or structure that is "natural" (or found in many of the world's languages; or acquired early by children) is said to be unmarked. On the other hand, a form that is "unnatural" (or not found in many of the world's languages; or is acquired late by children) is said to be marked. The following chart presents a survey of some of the research studies conducted within this framework in second language acquisition:

TABLE 1

\begin{tabular}{|ll|}
\hline Mazurkewicl: & $\begin{array}{l}\text { - L2 learner always reverts to default or unmarked } \\
\text { setting regardless of L1 setting }\end{array}$ \\
\hline Liceras: & •unmarked L1 parameters will transfer \\
\hline Phinney: & $\begin{array}{l}\text { - both marked and unmarked L1 parameter settings } \\
\text { will transfer } \\
\text { • easier for the learner to go from marked L1 setting } \\
\text { to unmarked L2 setting }\end{array}$ \\
\hline White: & $\begin{array}{l}\text { - both marked and unmarked L1 parameter settings } \\
\text { will transfer } \\
\text { - easier for the learner to go from unmarked L1 } \\
\text { setting to marked L2 setting }\end{array}$ \\
\hline
\end{tabular}

This has interesting consequences for second language acquisition in that both Phinney and White are claiming that some languages may, in fact, be more difficult to learn than others if they have selected a large number of marked parameter settings. Descriptive linguistics has traditionally taken the stand that all languages are equally complex, overall. A particular language may have a more complicated verb system than another language but it would have a simpler syntax. These claims may force linguists to reassess that claim.

\section{Pinker's Criteria and Parameter Setting}

Let us briefly consider a parameterized model of universal grammar in light of Pinker's conditions.

1. The Learnability Condition. One of the principal motivations of 
this model was that it be learnable in a way that previous generative grammars were not. Given the evidence presented in favour of a rationalist learning mechanism which constrains the hypothesis space of the learner, it meets this condition.

2. The Equipotentiality Condition. A parameter setting model of UG meets this condition well as it is primarily concerned with determining the characteristics of the common innate endowment of humans in the domain of language.

3. The Time Condition. As with other models, I would say that it is difficult to assess the principles and parameters model with respect to this condition, until more empirical work is done investigating actual learner behaviour within this framework.

4. The Input Condition. Crucially, this model is dependent on typical input that the learner receives. It follows the assumption that the learner does not make use of negative evidence.

5. The Developmental Condition. As with other models, little work has been done within this framework drawing on developmental data. The work that has been done does seem to show that the model can describe learner systems.

6. The Cognitive Condition. There is much support for the kind of cognitive architecture assumed by this model. We have already seen the kinds of advantages that a rationalist view of mind (and a rationalist learning theory) has over an empiricist account of the same facts. The area where a model such as this is open to criticism is the enormous amount of built-in (innate) knowledge which is assigned to the learner. Note, however, that this is an eminently testable claim. It is not avoiding the learning question to say that a particular property is innate; such a claim is easily falsifiable. If we discover one language that does not show evidence of a supposed innate universal then, obviously, we cannot argue that the property in question is, in fact, innate. Proposing that a property is innate is a very strong claim. This is another reason why more empirical studies are necessary in order to attest to the adequacy of this model.

\section{RESEARCH IMPLICATIONS}

The language learnability paradigm has become one of the dominant areas of research in first language acquisition. There is now a journal, Language Acquisition, that is devoted to work within this framework. And it is fast becoming a powerful force in second language acquisition research. Much of the work reported on in the journal Second Language Research is conducted within this model. To me, the language learnability paradigm is an appealing one 
because it makes explicit, falsifiable claims. True, the empirical results are not always what the model would predict, but it is clear what the model would predict. This is good theory. Much of the empirical confusion has stemmed from the fact that the model of Chomsky's Government and Binding syntax (on which it draws freely) is changing rapidly. There is often debate as to what exactly is a principle, or what exactly is a parameter. But those of us who are interested in language acquisition, and language teaching, cannot sit around and wait for the day when theoretical linguistics stabilizes and comes up with the answers. That day will never come. The model can still tell us a great deal about language learning.

With a certain amount of background knowledge, second language teachers can have access to this literature. Of course, the pedagogic implications may not always be immediately obvious, and will almost surely not be explicitly stated. But the language teacher can decide what aspects of the research are relevant to a particular classroom.

\section{PEDAGOGIC IMPLICATIONS}

One of the major implications of this paradigm for those of us working in applied fields is the realization that theoretical linguistics and language acquisition are no longer isolated disciplines. Traditionally, theoretical linguists were concerned with describing the grammars of native-speaker adults; they were not as concerned with how the knowledge got there. That domain of inquiry was left primarily to researchers working within a psychological paradigm. But now things have changed. Theoretical linguistics and acquisition studies are feeding off one another. The recent book edited by Huebner and Ferguson (1991) is further evidence of this.

Another pedagogic implication is closely tied to a productive line of research in traditional second language acquisition studies. Second language researchers and teachers alike have long been concerned with the question of error correction (Tomasello \& Herron, 1988, 1989; Woods, 1989; Van Patten, 1988; Higgs \& Clifford, 1982). What effect does error correction, when it is focussed on form have on the second language learner? The empirical studies have not showed any clear support for the claim that error correction increases the accuracy of the students. Within the UG framework there is a line of research that could be relevant to this question. As we have seen, a rationalist learning theory assigns the environment a triggering function. The environment does not shape the mind, but triggers what is already there. Some researchers (Lightfoot, 1991; Dresher \& Kaye, 1990; Archibald, 
1992) are looking closely at what the triggering experience in language acquisition is. What are the triggers that would cause a learner to reset a parameter? It appears that certain kinds of input will be relevant to resetting particular parameters. As of yet, the discussions of the triggering experience are quite technical and related to specific parameters, but I strongly feel that generalizations are coming. As we build up to a critical mass of evidence as to what kinds of input trigger the resetting of several different parameters, we will be in the position to make general statements as to the effect of the input on the learner.

\section{CONCLUSION}

In this paper, we have seen how such disciplines as philosophy, psychology and linguistics can influence the determination of a viable theory of language acquisition. The problems with empiricist, constructivist, inductive learning theories were presented and the benefits of a rationalist, innatist, deductive theory were expounded. A particular version of a theory of this type, namely parameterized universal grammar was briefly outlined and proposed as a viable theory of language acquisition.

This theory is beginning to have a very strong impact on the kind of research being conducted in second language acquisition. I feel that it is necessary for second language teachers to have some understanding of the basic issues involved. Otherwise they run the risk of being cut off from a very rich source of information. The pedagogic implications of this research are not usually spelled out by the researchers. The current trend toward viewing classroom teachers as classroom researchers puts the teacher in a privileged position to investigate how this research paradigm could affect second language education.

\section{NOTE}

1. Where the subscripts indicate coindexing, and the $t$ represents an empty category (or trace) left behind after the wh-word has moved from the underlying position to the frong of the sentence. Coindexing is used to indicate that two elements in a syntactic tree refer to the same referent, e.g., "Bob; thought that he; was smart" indicates that Bob thought that Bob was smart, whereas "Bob thought that he $\mathrm{j}_{\mathrm{j}}$ was smart" would indicate that Bob thought that somebody else was smart. 


\section{THE AUTHOR}

John Archibald is Assistant Professor in the Department of Linguistics at the University of Calgary. He specializes in second language acquisition and universal grammar. His book Language Learnability and Phonology: the Acquisition of L2 Metrical Parameters is being published by Kluwer next year.

\section{REFERENCES}

Archibald, J. (1992). The role of feedback in parameter resetting in adult second language learners. Paper presented at the American Association of Applied Linguistics annual conference in Seattle, Washington.

Baker, C. L. (1979). Syntactic theory and the projection problem. Linguistic Inquin, $10(4), 533-582$.

Bley-Vroman, R. \& Chaudron, C. (1990). Second language processing of subordinate clauses and anaphora-first language and universal influences: a review of Flynn's research. Language Learning 40(2), 245-285.

Braine, M. (1971). On two types of models of the internalization of grammars. In D. Slobin (Ed.). The ontogenesis of grammar. Academic Press.

Brown, R. \& Hanlon, C. (1970). Derivational complexity and the order of acquisition in child speech. In J.R. Hayes (Ed.), Cognition and the development of language (pp. 11-53). Wiley.

Carroll, S. (1989). Language acquisition studies and a feasible theory of grammar. Canadian Joumal of Linguistics 34(4), 399-418.

Chomsky, N. (1983). Noam Chomsky's views on the psychology of language and thought. In R.W. Rieber (Ed.), (pp. 29-64).

Chomsky. N. (1984). Modular approaches to the study of mind. San Diego: San Diego State University Press.

Chomsky, N. (1986). Knowledge of language. New York: Praeger.

Chomsky, N. (1988). Language and problems of knowledge. Cambridge: MIT Press.

Cook, V. J. (1988). Chomsky's universal grammar. Cambridge, MS: Basil Blackwell.

Curtiss, S. (1977). Genic: A psycholinguistic study of a modern-day "wild child". Academic Press.

Curtiss, S. (1988). Abnormal language acquisition and the modularity of language. In F. Newmeyer (Ed.), Linguistics: The Cambridge Suncy, volume 2 (pp. 96-116).

Demopoulos, W. (1989). On applying learnability theory to the rationalismempiricism controversy. In Mathews and Demopoulos (Eds.) (pp. 77-88).

Dresher, B. Elan \& Kaye, J. (1990). A computational learning model for metrical phonology. Cognition 34, 137-195.

Flynn, S. (1987). A paraneter-setting model of L2 acquisition. Dordrecht: D. Reidel.

Fodor, J. (1983). The modulariy of mind. Cambridge: MIT Press.

Gardner, H. (1980). Foreward to M. Piattelli-Palmarini, ed. (1980).

Garfield, J. L. (1987). Modularity in knowledge represchtation and natural-language understanding. Cambridge: MIT Press.

Gleitman, L., Newport. E. \& Gleitman, H. (1984). The current status of the motherese hypothesis. Joumal of Child Langrage II, 43-79.

Gold, E. M. (1967). Language identification in the limit. Information and Control $X$, 447-474.

Higgs, T. V. \& Clifford, R. (1982). The push toward communication. In T.V. Higgs (Ed.), Cumiculum, competence, and the foreign language teacher. National Textbook Company in association with ACTFL. 
Hornstein, N. \& Lightfoot, D. (Eds.) (1981). Explanation in linguistics: the logical problem of language acquisition. Longman.

Huebner, T. \& Ferguson, C. (Eds.). (1991). Crosscurrents in second language acquisition and linguistic theories. Amsterdam: John Benjamins.

Jackendoff, R. (1987). Consciousness and the computational mind. MIT Press.

Jacob, F. \& Monod, J. (1961). Genetic regulatory mechanisms in the synthesis of proteins. Joumal of Molecular Biology 3, 318.

Lasnik, H. (1989). On certain substitutes for negative evidence. In Mathews \& Demopoulos (Eds.).

Liceras, J. (1989). On some properties of the "pro-drop" parameter. In S. Gass and J. Schachter (Eds.), Linguistic perspectives on second language acquisition (pp. 109133). Cambridge: Cambridge University Press.

Lightfoot, D. (1991). How to set parameters: Arguments from language change. Cambridge: MIT Press.

Lightfoot, D. (1982). The language lottery. Cambridge: MIT Press.

Mathews, R. (1989). The plausibility of rationalism. In Mathews \& Demopoulos (Eds.), (pp. 51-76).

Mathews, R. \& Demopoulos, W. (Eds.) (1989). Learnability and linguistic theory. Dordrecht: Kluwer.

Mazurkewich, I. (1984). The acquisition of the dative alternation by second language learners and linguistic theory. Language Leaming 34, 91-109.

Newport, E., Gleitman, L. \& Gleitman, H. (1977). Mother, l'd rather do it myself: some effects and non-effects of maternal speech style. In C. Snow \& C. Ferguson (Eds.), Talking to children: Langutage input and acquisition (pp. 177-210). New York, NY: Cambridge University Press.

Phinney, M. (1987). The pro-drop parameter in second language acquisition. In Roeper \& Williams, (Eds.) (pp. 221-238).

Piattelli-Palmarini, M. (Ed.). (1980). Language and learning: The debate between Jean Piaget and Noam Chomsky. Cambridge: Harvard University Press.

Pica. T. \& Doughty, C. (1985). Input and interaction in the communicative classroom: a comparison of teacher-fronted and group activities. In S. Gass \& C. Madden (Eds.), Input in second language acquisition. Newbury House.

Pinker, S. (1979). Formal models of language learning. Cognition 1, 217-283.

Pinker, S. (1989). Language keamability and cognition: The acquisition of argument structure. Cambridge: MIT Press.

Tomasello, M. \& Herron, C. (1988). Down the garden path: inducing and correcting overgeneralization errors in the foreign language classroom. Applied. Psycholingzistics 9, 237-246.

Tomasello. M. \& Herron. C. (1989). Feedback for language transfer errors: the garden path technique. Studies in Second Language Acquisition 11, 385-395.

Roeper, T. \& Williams, E. (Eds.). (1987). Parameter setting. Dordrecht: D. Reidel.

VanPatten, B. (1988). How juries get hung: problems with the evidence for a focus on form in teaching. Langtage Learning 38, 243-260.

White, L. (1989). Universal grammar and second language acquisition. Amsterdam: John Benjamins.

Williams, E. (1987). Introduction to Roeper \& Williams (Eds.)

Woods, D. (1989). Error correction and the improvement of language form. TESL Canada Jounnal 6(2), 60-73. 